\title{
Formação Inicial do Professor de Matemática no Contexto das Tecnologias Digitais
}

\author{
Marcelo Souza Motta
}

\begin{abstract}
Resumo
Este artigo apresenta um recorte de uma pesquisa de doutoramento que teve como objetivo verificar se ambientes mediados por computador contribuem na formação inicial de acadêmicos de um curso de Licenciatura em Matemática. A pesquisa, em sua fase inicial, foi estruturada em duas etapas: a primeira investigou os acadêmicos durante a formação inicial em uma disciplina de concepções tecnológicas e pedagógica, e a segunda foi realizada durante 0 desenvolvimento das atividades de Estágio Obrigatório em escolas do Ensino Médio. Neste artigo, a abordagem se dará somente na primeira etapa da investigação. 0 quadro teórico desta investigação buscou aporte de pesquisadores da formação inicial de professores, atividades investigativas, tecnologias educacionais e aprendizagem significativa. Como processo investigativo, utilizou-se um método qualitativo descritivo, com a aplicação de variados instrumentos metodológicos. Os resultados mostram que a utilização de tecnologias na formação inicial dos acadêmicos da Licenciatura em Matemática promove impactos significativos em sala de aula e cria um ambiente que proporciona aos alunos novas formas de pensar e agir.
\end{abstract}

Palavras-chaves: Tecnologias educacionais. Formação inicial. Matemática.

\section{INITIAL FORMATION OF MATHEMATIC TEACHER IN THE CONTEXT OF DIGITAL TECHNOLOGIES}

\begin{abstract}
This article presents a synthesis of a doctoral research and aims to verify if computer- mediated environments contribute to the initial training of academics of a Mathematics Course. The research, in its initial phase, was structured in two stages. The first phase investigated the academics during the initial formation in a discipline of technological conceptions and the second one was carried out during the development of supervised internship activities in high schools. In this article, the focus will be on conducting research in the first stage. The theoretical framework of this investigation required the input of researchers from initial
\end{abstract}


teacher education, research activities, educational technologies, meaningful learning and conceptual maps. A qualitative descriptive method was used as an investigative process, using a variety of methodological tools. The results show that the use of technologies, in the initial training of undergraduate students in Mathematics, promotes significant impacts in the classroom and creates an environment that gives students new ways of thinking and acting.

Keywords: Digital Technologies. Initial Formation. Mathematics. 
Ao refletirmos sobre o uso das tecnologias digitais no contexto escolar das aulas de matemática, devemos buscar uma maneira de tornar a utilização desses recursos uma atividade experimental rica, em que o aluno é instigado a desenvolver seus processos matemáticos fundamentais, caracterizando um fazer matemático significativo.

Para que a integração da Matemática com as tecnologias torne a sala de aula um espaço reflexivo, lúdico, comunicativo e potencializador de formas de expressões criativas, faz-se necessário termos um olhar crítico e analítico para a formação inicial do professor de matemática.

Para Motta e Silveira (2012) a formação inicial é fundamental para que a transposição entre as tecnologias digitais e os conteúdos matemáticos ocorra de forma a apresentar subsídios teóricos e metodológicos para o uso das ferramentas tecnológicas no ensino.

Neste contexto, este trabalho apresenta um recorte de uma pesquisa de Doutorado, que buscou observar e analisar as interações de alguns acadêmicos de um curso de Licenciatura em Matemática com alguns softwares educacionais em uma disciplina específica da Graduação. Como consequência desta interação, verificamos o reflexo dessa ação na prática do Estágio Obrigatório com alunos do Ensino Médio de escolas públicas.

Considerando a quantidade de informações presentes naquela pesquisa, apresentaremos apenas a primeira etapa do estudo, que teve como objetivo compreender se o uso de tecnologias digitais contribui na formação inicial dos acadêmicos de um curso de Licenciatura em Matemática.

A pesquisa foi realizada com sete acadêmicos de uma universidade pública do Mato Grosso do Sul, que cursavam o último semestre do curso e possuíam em sua grade curricular as disciplinas de Informática Aplicada ao Ensino de Matemática e Estágio Obrigatório no Ensino Médio II.

Este estudo se apresentou como uma pesquisa qualitativa descritiva, pois não possuíamos a intenção de quantificar os resultados, mas identificar e analisar as possíveis contribuições da utilização de ambientes mediados por computador na formação inicial dos acadêmicos de um curso de Licenciatura em Matemática. 
Para atingir o objetivo proposto, foi necessária a identificação dos percursos seguidos no decorrer desta investigação, realizando um confronto entre os procedimentos metodológicos, as observações e informações coletadas e o conhecimento teórico.

A investigação contribui com a reflexão de que o uso de tecnologias digitais durante a formação inicial dos acadêmicos de Matemática possibilita um repensar da prática pedagógica, tornando os conceitos matemáticos significativos e os acadêmicos sujeitos ativos e reflexivos na construção de sua aprendizagem.

\section{Metodologia da Pesquisa}

Para podermos responder às questões levantadas por este artigo, faz-se necessário que identifiquemos os percursos que seguiremos no decorrer da pesquisa. Como afirmam Lüdke e André (2013), para se realizar uma pesquisa é preciso promover o confronto entre os dados, as evidências, as informações coletadas sobre determinado assunto e o conhecimento teórico acumulado a respeito dele.

O grande desafio das pesquisas educacionais é analisar essa realidade ativa e intricada, de forma a captar a essência dos objetos de estudo. Assim, optamos, neste estudo, por realizar uma pesquisa qualitativa descritiva, pois buscamos descrever, empregando vários procedimentos, a experiência dos acadêmicos com o uso de tecnologias digitais, proporcionando uma nova visão da utilização desses recursos em suas realidades.

Cabe destacar, como já mencionado anteriormente, que aquela pesquisa ocorreu em duas etapas. A primeira foi realizada no segundo semestre de 2012, em uma disciplina de 68 horas, com quatro aulas semanais, e com atividades realizadas no laboratório de informática. A segunda etapa também ocorreu no segundo semestre de 2012, concomitante com a primeira etapa, durante as aulas de Estágio Obrigatório no Ensino Médio II, com carga horária de 119 horas. 
Este artigo tratará apenas da primeira fase da pesquisa. Esta etapa buscou compreender a ementa da disciplina de Informática Aplicada ao Ensino de Matemática e realizou alguns ajustes na organização do curso e nos softwares educacionais utilizados. Com base nos objetivos, no programa da disciplina e nas turmas de realização do Estágio Obrigatório estabeleceu-se que os softwares estudados fossem: SuperLogo, Winplot, Geogebra, Planilhas Eletrônicas (Microsoft Excel) e Poly.

Usamos diferentes procedimentos metodológicos, dentre os quais se destacam: mapas conceituais, observações, questionários, relatórios e atividades investigativas.

Os mapas conceituais foram aplicados no início (mapa conceitual inicial) e ao término da investigação (mapa conceitual final). Inicialmente procurou-se identificar os conhecimentos prévios dos graduandos sobre tecnologias digitais. Na finalização do estudo, foi solicitada a confecção de novo mapa, com a mesma temática, o que nos permitiu compreender as contribuições aos acadêmicos da disciplina Informática Aplicada ao Ensino de Matemática. Para Moreira (2013), a utilização de mapas conceituais permite entender como uma pessoa externaliza conceitos, relacionando-os com aquilo que ela sabe.

As observações foram constantes em todas as fases da pesquisa, pois facilitaram a compreensão da elaboração das tarefas pelos alunos. O tipo de observação utilizada foi a participante (BOGDAN; BIKLEN, 1994), pois o investigador interagiu e analisou os acadêmicos nas fases do estudo. Associadas à observação participante ocorreram anotações para produzir um melhor acompanhamento dos eventos ocorridos durante a realização da pesquisa.

Os questionários também foram ferramentas essenciais, pois tinham a finalidade de captar informações relevantes à pesquisa. Para Tuckman (1994), o uso do questionário, não sendo propriamente uma metodologia qualitativa, é particularmente útil quando queremos entender o que as pessoas sabem, do que gostam ou do que não gostam e o que pensam. 
Foram aplicados três questionários: o primeiro buscou caracterizar os acadêmicos e seus hábitos tecnológicos (Questionário 1), o segundo observou a interação dos acadêmicos com os softwares educacionais (Questionário 2) e o terceiro objetivou captar, ao término da pesquisa, as contribuições da utilização de tecnologias digitais na formação inicial (Questionário 3).

Os relatórios tinham como objetivo perceber ou esclarecer como os graduandos realizaram as tarefas, entendendo sua forma de interagir e pensar. Os relatórios foram confeccionados ao término da manipulação de cada um dos softwares, e destacavam os aspectos positivos e negativos do emprego da ferramenta e a forma como a mesma contribuiria com o desenvolvimento do Estágio Obrigatório no Ensino Médio II.

As atividades investigativas foram preparadas pelo investigador, tendo como base a Teoria das Situações Didáticas, as características de cada um dos softwares e a necessidade dos acadêmicos durante a realização das atividades de estágio.

No total, foram desenvolvidas cinco atividades contendo orientações sobre as ferramentas e suas potencialidades educacionais. É importante destacar que todas as atividades tiveram três fases distintas: $1^{\mathrm{a}}$ ) inicialmente, apresentamos o software com alguns exemplos de execução; $2^{\mathrm{a}}$ ) em seguida, os acadêmicos executaram as atividades desenvolvidas pelo investigador; e $3^{\mathrm{a}}$ ) finalizando, os acadêmicos produziram um relatório sobre a realização da tarefa.

Cada uma das atividades possuía objetivos claros e o desenvolvimento de algumas habilidades, das quais destacamos: reconhecer elementos das figuras planas e espaciais; desenvolver conceitos da geometria interativa; aprimorar os conceitos de funções; resolver problemas graficamente; trabalhar com transformações de grandezas; identificar conceitos algébricos e estatísticos em ferramentas computacionais, entre outros.

Por fim, todo o material recolhido ao longo do estudo foi organizado numa única documentação, submetida à análise. Para Lüdke e André (2013), é nesse momento que o pesquisador deve ter uma ideia clara das possíveis direções teóricas do estudo e partir para "trabalhar" o material acumulado, buscando destacar os principais aspectos revelados pela pesquisa. 
Após a coleta e organização dos documentos, foram traçadas relações, semelhanças e padrões nas atividades produzidas pelos acadêmicos, na tentativa de perceber e esclarecer o objetivo geral.

\section{Formação Inicial do Professor de Matemática}

As Diretrizes Curriculares Nacionais para a Formação Inicial e Continuada dos Profissionais do Magistério da Educação Básica (BRASIL, 2015), afirmam que o professor deve agregar um conjunto de habilidades que somente podem ser estruturadas na vivência e na ação pedagógica cotidiana.

Os Cursos de Licenciatura em Matemática, segundo a Resolução CNE/ CES N 3 , de 18 de fevereiro de 2003, devem preparar o profissional para uma carreira docente na qual a Matemática seja abordada de forma significativa, e a formação pedagógica seja direcionada à sua prática, possibilitando vivenciar as mais diversas situações cotidianas da escola.

Os profissionais formados nos cursos de Licenciatura em Matemática devem, assim, ter uma visão abrangente da função social do professor, além de possuir a capacidade de pensar na aplicação das tecnologias em sala de aula, participar de estudos e grupos de formação continuada, compreender a Matemática presente nas situações cotidianas, identificar os conteúdos matemáticos e relacioná-los com as outras disciplinas, estabelecendo um trabalho interdisciplinar, e, por fim, devem expressar com clareza e objetividade os saberes técnicos necessários ao professor de Matemática.

Essa formação "deve contribuir para o desenvolvimento pessoal, para a tomada de consciência da responsabilidade no desenvolvimento da escola e dos alunos e para a aquisição de uma atitude reflexiva acerca dos processos de ensino e de aprendizagem" (MARCELO GARCÍA, 1999, p. 80). Dessa forma, o educador terá um papel significativo, garantindo uma formação inicial com base na ação docente e suas diferentes percepções e saberes.

Para Shulman et al. (1987), os professores precisam estruturar pontes entre o significado do conteúdo curricular e aquele compreendido pelos alunos. Fazer essa transposição não é uma tarefa trivial, posto que o docente precisa 
ter certa flexibilidade e compreensão sobre os componentes curriculares da Matemática, para que perceba as dificuldades apresentadas pelos alunos durante o processo. Dessa maneira, quando necessário, o docente poderia realizar mudanças no planejamento, revendo metodologias e procedimentos adotados.

À medida que o docente interage e enriquece sua prática, sua atuação pedagógica está em constante ampliação. Dessa forma, a construção de uma base sólida na formação inicial deve apresentar uma diversidade de saberes em diferentes concepções, permitindo ao professor interagir em sua realidade, além de proporcionar uma variedade de conteúdos específicos promovendo uma ação eficaz nos processos de ensino e aprendizagem.

Nesse sentido, o saber pedagógico desempenha uma função primordial na constituição do conhecimento docente, que somente se efetivará se o professor ampliar sua consciência sobre a própria prática, a de sala de aula e a da escola como um todo.

Assim, conforme destacam Motta e Silveira (2012), espera-se que os cursos de Licenciatura em Matemática promovam em suas matrizes curriculares maior ênfase na formação pedagógica e no uso adequado das tecnologias digitais, promovendo um diálogo entre as disciplinas específicas e as práticas.

\section{Formação Inicial do Professor de Matemática no Contexto das Tecnologias}

Para Tajra (2012), a utilização das tecnologias tem sido objeto de vários estudos no campo educacional, proporcionando modificações e reestruturações do processo educacional. Nessa perspectiva, alterações têm ocorrido no cotidiano das escolas, fazendo com que o professor assuma uma nova postura perante os recursos tecnológicos disponíveis. Beline e Costa (2010) argumentam que a formação do professor necessita prepará-lo criticamente, para que a introdução das tecnologias digitais contribua com implicações sociais e psicológicas nos processos de ensino e aprendizagem. 
Dentre essas mudanças, a Matemática deve buscar estratégias metodológicas com o apoio das tecnologias, de forma a criar situações que façam do aluno agente ativo na construção de sua própria aprendizagem. Para Borba e Penteado (2015), com a introdução e provável supremacia da informática enquanto mídia haverá modificações nos caminhos que nos levam às verdades matemáticas aceitas pela comunidade acadêmica. Para os autores, as novas práticas pedagógicas permitem que mais estudantes tenham acesso aos conteúdos matemáticos e à resolução de problemas, criando uma relação entre seres humanos e computadores.

Assim, o uso do computador contribui para que os processos de ensino e aprendizagem da Matemática se tornem uma atividade experimental e rica, quando instiga o educando a desenvolver processos fundamentais que caracterizam o fazer matemático, tais como experimentar, interpretar, visualizar, induzir, conjecturar, abstrair, generalizar, demonstrar, dentre outros.

Nesse contexto, a Matemática está amplamente relacionada com as tecnologias digitas, pois ela é a base estrutural dos processos de informação e comunicação, e o pensamento matemático é referência para as aplicações de modelos tecnológicos.

Com o uso dos recursos tecnológicos, o professor desempenha um papel fundamental na elaboração de estratégias centradas na experimentação que proporcionam ao educando um ambiente de trabalho que amplia seu próprio conhecimento. Para que isso ocorra, faz-se necessário que o professor escolha as ferramentas informatizadas adequadas.

O docente precisa estabelecer conexões entre o conteúdo matemático e a tecnologia, a fim de ultrapassar os obstáculos epistemológicos que o uso do computador poderá criar em uma sala de aula. 
Nesse sentido, ao analisarmos a grade curricular do curso de Licenciatura em análise, verificamos que, em sua estrutura, apresenta quatro disciplinas que se relacionam com as tecnologias digitais. São elas: Introdução a Ciências da Computação, Informática Aplicada ao Ensino de Matemática, Análise de Softwares Educacionais e Estrutura de Dados.

A disciplina Informática Aplicada ao Ensino de Matemática é estudada no último período do curso e somente passou a integrar a grade da Licenciatura no decorrer daquela investigação. Antes de 2012 o curso apresentava, em sua matriz curricular, apenas disciplinas de cunho tecnológico, sem nenhuma preocupação com os aspectos pedagógicos inerentes à interação do acadêmico com a tecnologia.

Cabe destacar que a estrutura curricular do curso é constituída de componentes que visam desenvolver nos acadêmicos os mais diversos saberes, competências e habilidades, que são de cultura geral e profissional, formação específica, formação pedagógica, dimensões práticas e formação complementar.

Notou-se, contudo, que não existe uma conexão entre as disciplinas de dimensão prática (Prática de Ensino, Estágio Obrigatório, entre outras) e o uso de tecnologias digitais. Tal fato fora evidenciado ao se verificar o projeto pedagógico do curso, pois, das disciplinas tecnológicas, somente duas são obrigatórias, e dessas apenas uma se relaciona diretamente ao uso das ferramentas tecnológicas com o Ensino de Matemática.

Acreditamos que uma estrutura curricular, como a da licenciatura em análise, contribui para uma formação significativa de seus alunos, não dissociando teoria e prática, mas apresenta, ainda, uma defasagem no que se refere ao uso de tecnologias digitais, principalmente na utilização das mesmas no cotidiano escolar.

Assim, percebeu-se a necessidade de as Instituições de Ensino Superior repensarem suas atividades práticas de ensino, de forma a explorar durante todo o curso o emprego de tecnologias, possibilitando aos futuros professores a construção e aplicação de conceitos matemáticos significativos. 
Uma das ferramentas tecnológicas que representa um grande potencial no Ensino de Matemática são os softwares educacionais, ${ }^{1}$ pois, quando bem-escolhidos e empregados, auxiliam o processo de aprendizagem e raciocínio, abrem perspectivas de trabalho, valorizam a resolução de problemas, tornam as ideias matemáticas significativas e fazem com que o aluno pense a respeito de si mesmo, sendo agente ativo de sua própria aprendizagem.

Durante a realização daquela investigação procuramos escolher softwares que desenvolvessem as atividades cognitivistas e que possibilitasse ao aluno o desenvolvimento do seu pensamento e a possibilidade de "pensar e repensar" seus próprios modelos.

Os softwares educacionais foram definidos de acordo com os conteúdos que seriam trabalhados pelos acadêmicos durante as aulas de Estágio Obrigatório. Os softwares empregados nesta pesquisa foram: Geogebra, SuperLogo, Winplot, Poly e Planilhas Eletrônicas.

\section{Concepções Teóricas}

As concepções teóricas utilizadas neste estudo, considerando apenas a primeira etapa daquela pesquisa, buscou dar o aporte teórico às interações entre os conceitos e o uso de recursos tecnológicos, ao desenvolvimento e execução das atividades investigativas e à avaliação de mapas conceituais. As fundamentações utilizadas foram a Teoria da Aprendizagem Significativa de Ausubel (1968) e a Teoria das Situações Didáticas de Brousseuau (1996).

Apresentaremos, sucintamente, alguns pontos destas teorias que possuem convergência com nossos estudos.

\footnotetext{
${ }^{1}$ A definição de software educacional que adotamos neste estudo é a de Motta (2012). Para o autor, "softwares educacionais são ferramentas que possuam em seu processo de elaboração uma preocupação com as questões pedagógicas, criando um ambiente crítico no qual o educando tem a oportunidade de desenvolver seu pensamento e raciocínio lógico" (p. 83-84).
} 
O termo aprendizagem é muito complexo para ser explicado de forma explícita, pois se relaciona com vários pressupostos políticos, ideológicos, socioculturais, concomitantes com as visões de mundo. De uma forma simplista, afirmamos que aprendizagem é a forma como os seres humanos adquirem novos conhecimentos, desenvolvendo técnicas e competências, mudando o seu dia a dia ou adaptando-se a ele.

O tipo de aprendizagem que utilizaremos nesta pesquisa é a aprendizagem por conceitos. Nesse tipo, os seres humanos têm grande tendência a interiorizar seu meio ambiente e pensar nele de várias maneiras. Aprender um conceito significaria, então, aprender a responder a estímulos, e, para que isso possa ser desenvolvido de forma satisfatória, necessitamos de certa variedade de situações estimuladoras apresentadas pelo educador.

Essa é a principal ideia da Aprendizagem Significativa desenvolvida por David Ausubel (1968): relacionar conceitos predefinidos ou predeterminados que já existem em uma estrutura a outro conceito novo, recém-adquirido pelo aluno e que tenha significado para ele. Moreira e Masini (1982, p, 47) asseveram que, para Ausubel, "a organização e a integração destes conceitos na estrutura cognitiva do aluno, é que significa aprendizagem".

Assim, afirmamos que a Aprendizagem Significativa acontece quando novas informações e ideias entram em interação com conceitos definidos que fazem parte da estrutura cognitiva do aluno, que por ele possam ser assimiladas, fortalecendo, assim, sua aprendizagem.

A ideia central dessa teoria é a de que o mais importante neste processo de aprendizagem "é o conhecimento que o aluno já possui, no qual a informação será ancorada a conceitos relevantes existentes, aos quais se denomina subsunçores" (AUSUBEL; NOVAK; HANECIAN, 1978, p. 38).

A teoria de Ausubel é essencial nesta pesquisa, pois estuda a maneira como o aluno relaciona as novas informações adquiridas com sua estrutura cognitiva, o que torna a aprendizagem mais significativa. 
Assim, com o aporte da teoria ausubeliana, pretendemos evidenciar que a utilização de um recurso intrínseco ao aluno, como os softwares educacionais, torna a Aprendizagem Significativa.

Para estruturar as atividades investigativas durante a manipulação dos softwares, usamos como aporte teórico a Teoria das Situações Didáticas (TSD). Para Almouloud (2007), a TSD busca criar um modelo de interação entre o aprendiz, o saber е о milieu (ou meio), na qual a aprendizagem deve-se desenrolar. Segundo o autor, o processo de aprendizagem "é constituído por uma ou várias situações que podem frequentemente conduzir a um processo de modificação dos comportamentos" (ALMOULOUD, 2007, p. 18).

Aí reside a proposta central dessa teoria: desenvolver um conjunto de situações que instiguem alterações comportamentais a partir dos conhecimentos adquiridos. O sujeito, nessa teoria, deixa de ser o centro das ações e a situação apresentada é vista como fator principal no processo de desenvolvimento cognitivo.

Nessa perspectiva, o aluno aprende adaptando-se a um meio que é uma situação repleta de problemas, de intrigas e dificuldades, trazendo para o seu dia a dia um pouco do que acontece na sociedade.

A etapa na qual o aluno interage com os problemas propostos pelo professor é denominada de situação didática; aquela cuja intenção de ensinar não é apresentada ao aluno, é denominada de situação adidática.

A situação adidática provoca no aluno a capacidade de transformar, abstrair, generalizar, avaliar, visualizar e resolver situações-problema, processos esses essenciais ao desenvolvimento matemático e pessoal. Essa teoria provoca no aluno a capacidade de pensar seus problemas fora do ambiente escolar, o que é, aliás, uma das grandes vantagens desta proposta educacional.

Brousseau (1996) destaca que os alunos não podem resolver qualquer situação adidática de imediato, e que o professor tem o compromisso de fornecer ao estudante as situações que estejam ao seu alcance. 
Existem quatro fases distintas na Teoria das Situações Didáticas. As três primeiras fases encaixam-se nas fases adidáticas (ação, formulação e validação) e a última ocorre a partir da interação do professor com o meio (institucionalização).

Cada uma das fases propostas por Brousseau (1996) foi usada nas atividades desenvolvidas pelo pesquisador. Como tivemos a pretensão de analisar as contribuições do uso de tecnologias na formação inicial em um curso de Licenciatura em Matemática, pareceu-nos interessante que as atividades tivessem uma ação investigativa, tornando o acadêmico agente ativo e reflexivo na construção de sua própria aprendizagem.

\section{Análise e Discussões dos Resultados Durante a Primeira Etapa da Pesquisa}

Nosso objetivo, ao dividir esta pesquisa em etapas, foi construir e destacar fatos marcantes dos quais participamos no desenvolvimento da coleta de dados, além de possibilitar um refinamento das questões parciais que atendam ao objetivo central.

Para a análise, os acadêmicos foram identificados por letras maiúsculas do alfabeto, a saber: A, B, C, D, E, F e G.

Dentre os vários questionamentos realizados na fase inicial da pesquisa, o que nos chamou mais atenção foi o fato de a maioria dos acadêmicos considerarem o computador apenas uma ferramenta de pesquisa ou digitação, demonstrando uma visão reducionista do uso da informática no ensino, pois se limitam a considerar o computador uma máquina de ensinar, e o aluno um ser passivo que recebe a instrução (grifo nosso).

Observamos que, em virtude de questões regionais, esses alunos não tiveram acesso às informações de forma rápida e em rede. Percebemos, ainda, nas observações realizadas durante a fase investigativa, que esses acadêmicos tinham comportamentos de "imigrantes digitais", pois não se sentiam seguros com o uso da informática e tinham dificuldades em realizar tarefas pelo computador. 
A análise do questionário inicial trouxe-nos algumas informações que podem ser cruzadas com os dados coletados ao longo da pesquisa. Uma constatação fica evidenciada: existe uma lacuna na formação inicial no que se refere ao uso de tecnologias digitais e sua consecução no Ensino de Matemática.

Para melhor caracterizar essa afirmação, analisamos os mapas conceituais iniciais desenvolvidos pelos acadêmicos, as interações com os softwares, os mapas finais e os questionários.

\section{O que Dizem os Mapas Conceituais Iniciais?}

Inicialmente foi solicitado aos acadêmicos que representassem seu conhecimento de tecnologias em um mapa conceitual. Na Figura 1 destacamos os mapas desenvolvidos pelos acadêmicos.

Observamos que todos os mapas seguiram uma linha parecida de construção. Os acadêmicos A, B e C tentaram apresentar uma concepção relacionando tecnologia com Educação, mas suas aplicações foram inconclusivas ou inconsistentes.

Os acadêmicos D, E e F apresentaram várias aplicações das tecnologias da informação, destacando suas contribuições a diversos campos e de forma modesta na Educação. $\mathrm{O}$ acadêmico $\mathrm{G}$ relacionou seu mapa somente a aplicações técnicas, não vislumbrando aplicações educacionais do uso de tecnologias.

Quanto ao uso do computador na Educação, nenhum dos mapas conceituais apresentava uma relação consistente entre os recursos tecnológicos disponíveis e as possíveis aplicações aos conhecimentos matemáticos. A ideia do uso de tecnologias numa perspectiva significativa surge apenas no mapa do acadêmico $\mathrm{C}$, apesar de necessitar de uma melhor organização das ideias.

Em contrapartida, apenas o acadêmico $\mathrm{F}$ trouxe à tona, em seu mapa, as ideias de tecnologias relacionadas ao uso de softwares, ainda que totalmente numa visão técnica. 
Figura 1 - Mapas conceituais iniciais sobre tecnologia
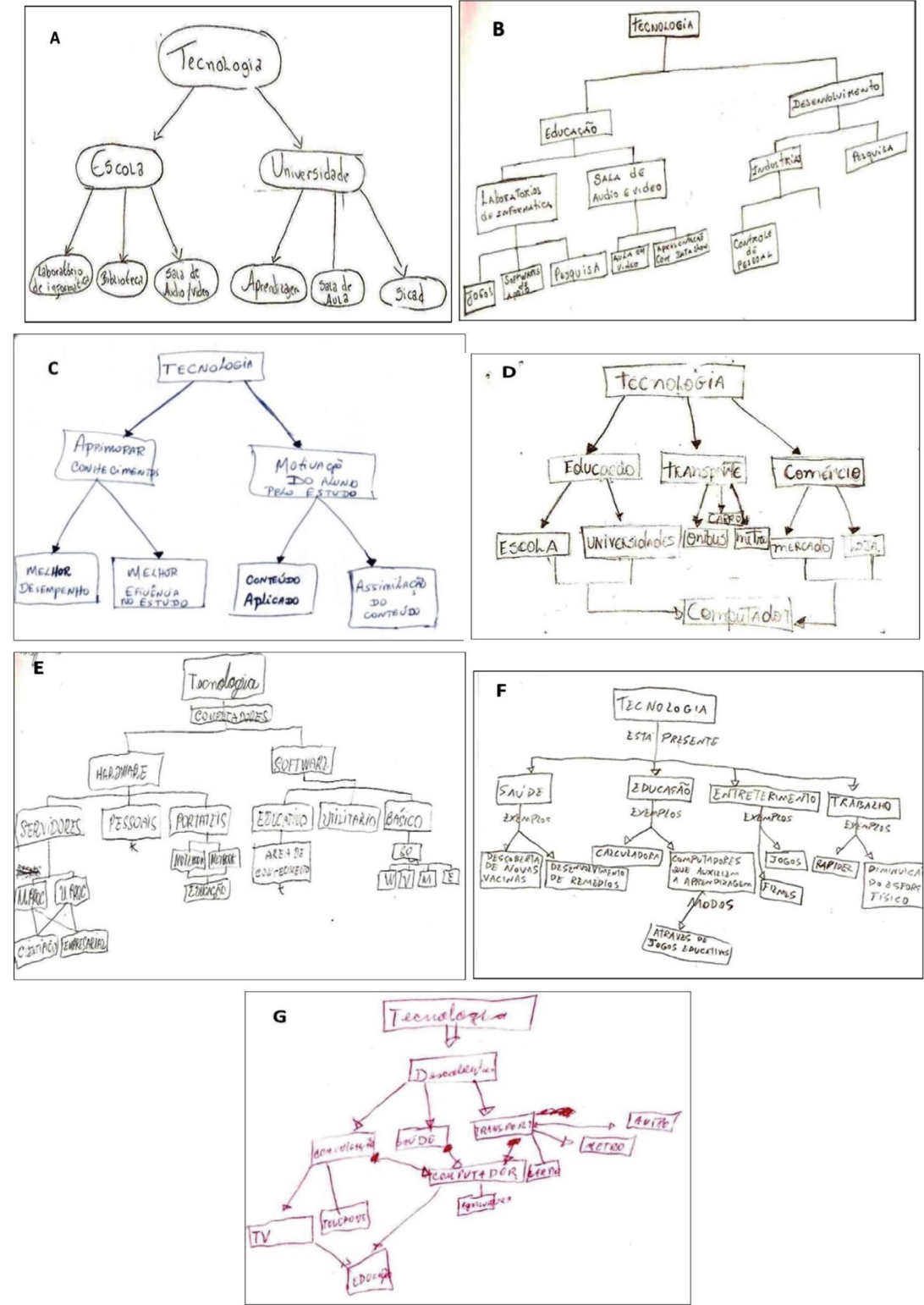
De maneira geral, como já era esperado, observamos que os mapas conceituais iniciais se apresentaram com poucos elementos que pudessem denotar o conhecimento dos acadêmicos sobre o tema tratado. Termos e expressões surgiam nos mapas, mas de forma insípida, sem um estabelecimento de relações consistentes entre os membros, denotando um baixo conhecimento sobre a temática ou uma dificuldade para expressá-la por meio de mapas.

\section{Análise das Atividades Desenvolvidas Durante a Disciplina Informática Aplicada ao Ensino de Matemática}

Como apresentamos anteriormente, essa etapa ocorreu no segundo semestre letivo de 2012 durante a disciplina Informática Aplicada ao Ensino de Matemática. Esse curso tinha como objetivo expor as contribuições do uso de recursos tecnológicos na formação inicial do professor de Matemática.

Inicialmente, a disciplina trouxe uma concepção teórica sobre o uso da informática educacional e suas aplicações à Educação, não possibilitando ao acadêmico a interação com recursos tecnológicos práticos. Foram sugeridas à coordenação do curso, pelo docente, mudanças no direcionamento da disciplina, trazendo experimentos práticos e o uso significativo de softwares educacionais, o que foi prontamente aceito.

Para as interações que podem ocorrer durante a disciplina, foi criado um grupo de discussão por intermédio de uma ferramenta disponível no Google denominada Google Grupos. Nesse espaço os alunos realizaram interações e observações em todo o decorrer da investigação.

Assim, faremos uma análise sintética de cada um dos softwares aplicados, comentando algumas das atividades desenvolvidas, e uma análise final referindo-se às respostas dadas aos questionários de avaliação de softwares. 


\section{O software Geogebra}

O Geogebra é um software livre e de multiplataforma que alia Geometria interativa e Álgebra. Foi desenvolvido por Markus Hohenwater em 2001 na Universidade de Salzburg, sendo aperfeiçoado, posteriormente, na Atlantic University. O software utiliza uma construção dinâmica de figuras e objetos que auxiliam na compreensão de conceitos matemáticos por meio do desenvolvimento dos processos mentais de visualização, percepção, estímulo heurístico, abstração, depuração e análise de experimentos.

Para a utilização, no grupo de acadêmicos, aplicamos um instrumento contendo 22 tarefas executáveis e uma tarefa dissertativa, que visava à criação de uma atividade para aplicação em uma turma do Ensino Médio. Nosso objetivo, nas tarefas executáveis, era verificar em quais tarefas os alunos apresentavam maior dificuldade, e na tarefa dissertativa verificar a possibilidade de institucionalização dos conceitos matemáticos.

Observamos que os acadêmicos não mostraram dificuldades de resolução das atividades propostas. A principal contribuição do Geogebra está relacionada ao fato de o software ser interativo, possibilitando manipular e criar situações, obter conjecturas sobre o conteúdo proposto e gerar um ambiente investigativo durante a utilização do recurso.

Uma atividade que merece destaque no instrumento, e que possibilitou uma grande socialização entre os acadêmicos, foi:

23) Crie 4 seletores, $a, b, c, e d$, variando de -10 a 10, e construa a função $f(x)=a \cos (b x+c)+d$. Em seguida estude os coeficientes.

Nessa atividade os acadêmicos puderam interagir com os demais colegas mostrando e comentando as diferentes formas que seus gráficos poderiam assumir a partir do estabelecimento dos seletores, identificando pontos de crescimento e decrescimento, zeros da função, comprimento das ondas, dentre outros questionamentos. 
Outra atividade analisada foi a questão dissertativa, elaborada por cada acadêmico. De forma geral, as questões foram bem-desenvolvidas. Os acadêmicos A, B e D elaboraram atividades meramente aplicativas do software, não desenvolvendo o pensamento reflexivo e investigativo dos alunos.

Os acadêmicos C, E, F e G elaboraram questões envolvendo funções, por meio da elaboração do gráfico e análise da função de acordo com a inserção de seletores. Com essa tarefa, os acadêmicos possibilitaram aos estudantes do Ensino Médio investigar as diversas representações de um ponto no plano, permitindo a exploração livre de quaisquer valores de coordenadas que queiram atribuir a este, consolidando ou refutando possíveis conjecturas.

Esperávamos que durante essa atividade os acadêmicos mobilizassem o uso dos conceitos presentes na TSD, criando um espaço de interação entre o aluno, o saber e o Geogebra. O que evidenciamos em todas as tarefas foram tentativas de criação de situações didáticas. $\mathrm{O}$ que faltou, principalmente nas tarefas dos acadêmicos A, B e D, foi a criação de um meio pelo qual o aluno pudesse desenvolver os processos matemáticos essenciais ao pensamento matemático (abstração, generalização, visualização, avaliação, dentre outros).

Quanto às fases adidáticas, notamos sua presença tímida nas atividades dos acadêmicos C, E, F e G, permitindo ao estudante passar pelas etapas de ação, formulação e validação.

Sobre as contribuições do software, os acadêmicos destacam que o Geogebra faz com que o aluno visualize e altere dinamicamente suas construções. Os conteúdos matemáticos que podem ser desenvolvidos vão de conceitos básicos de geometria plana a conceitos algébricos avançados de uso no Cálculo Diferencial e Integral.

Todos os alunos avaliaram positivamente o software, e afirmaram que o Geogebra pode contribuir para sua prática docente, pois desenvolve construções detalhadas e bem-elaboradas, permite trabalhar com gráficos e funções e possibilita a aplicação em vários conceitos. 


\section{O software Poly}

O software Poly foi desenvolvido pela Pedagoguery Software. Ele possibilita a visualização de poliedros convexos, permitindo a manipulação, planificação e rotação. Possui diversos modelos predefinidos de sólidos platônicos, arquimedianos, prismas, antiprismas, sólidos de Jonhson, deltaedros, esferas e domos geodésicos.

O instrumento investigativo proposto foi composto por quatro tarefas executáveis diretamente no software. O desenvolvimento das atividades foi dificultado, pois está à disposição para download somente uma versão demonstrativa, que não permite utilizar todas as ferramentas do programa.

A maior contribuição do software Poly é o auxílio no processo de visualização de sólidos geométricos, possibilitando a identificação dos elementos de uma figura espacial, identificação de sólidos platônicos e estabelecimento da relação de Euler.

Por se tratar de um software simples e de fácil manipulação, os acadêmicos não tiveram dificuldades em realizar as tarefas. Ao término da execução das atividades, os acadêmicos destacaram a simplicidade do software e a possibilidade de utilizá-lo ao iniciar ou reforçar conteúdos de geometria plana ou espacial, contribuindo com o processo de visualização matemática.

Um aspecto positivo, observado pelo pesquisador na aplicação desse software, foi a iniciativa de alguns acadêmicos em elaborar um mapa conceitual sobre geometria espacial, pois consideraram que o Poly não apresentava uma metodologia suficiente para sanar possíveis dúvidas e conjecturas.

\section{O software WinPlot}

O Winplot foi criado pelo professor Richard Parris, da Philips Exeter Academy, em 1985. É um software eficaz para plotar gráficos de funções simples e complexas. O programa trabalha equações explícitas, polares, paramétricas 
e implícitas. Após estabelecer a função no Winplot, o usuário pode trabalhar com vários tipos de utilizações. Dentre eles, destacam-se: derivados, integrais, superfície de revolução, área entre gráficos, dentre outros.

$\mathrm{O}$ instrumento investigativo foi elaborado com quatro questões, numa perspectiva instigadora e significativa, tendo características básicas às fases da TSD, em que os acadêmicos puderam identificar as fases adidáticas de ação, formulação e validação.

Os acadêmicos tiveram algumas dificuldades em desenvolver as atividades propostas no WinPlot. Tais problemas ocorreram porque as tarefas foram elaboradas em diferentes níveis de dificuldade. O participante deveria passar por todas as fases adidáticas estabelecidas na perspectiva de Brousseuau (1996). Por vezes, as conjecturas estabelecidas eram refutadas, fazendo com que o acadêmico voltasse à fase de formulação.

Dentre as atividades desenvolvidas no Winplot, destacamos:

1) A expressão $N(t)=2(0,5)^{t}$, representa o nível de decrescimento do álcool no sangue de um determinado motorista, onde t é o tempo medido em horas. Depois de haver tomado umas cervejas, qual o tempo estimado para o motorista dirigir sem ser pego no teste do bafômetro, sabendo que o limite é de $0,8 g$ por litro?

Essa atividade apresenta todas as fases didáticas necessárias a uma boa aprendizagem de forma significativa, pois cria um ambiente de ação, no qual o acadêmico necessita interagir com o software para construir o gráfico da função exponencial. Após sua execução, o mesmo se depara com um gráfico expresso no WinPlot, mas que não apresenta uma resposta imediata, necessitando de processos matemáticos mentais para sua resolução. Dessa forma, o acadêmico tece conjecturas sobre a atividade, o que confirma a fase de formulação, estabelecendo uma situação adidática.

Na realização das atividades, no grupo de discussão, os acadêmicos acharam interessante a resolução de atividades dentro da proposta da TSD, pois tiveram de pensar na forma que deveriam agir, propor e interagir com as tarefas. 
Desse modo, ocorreu uma aprendizagem significativa, pois os participantes construíram seu conhecimento mediante uma proposta investigativa, contextualizada e que apresentou o conteúdo de forma ativa dando significado ao que estava sendo aprendido.

Ao término das atividades, os alunos avaliaram as contribuições do software. Sobre a utilização do Winplot na prática docente, seis alunos afirmaram que o mesmo contribuirá nas suas aulas, pois possibilita o trabalho com diversos conceitos, simplifica os cálculos e desenvolve processos matemáticos mentais.

\section{O software SuperLogo}

A linguagem Logo foi desenvolvida nos EUA, no Massachusetts Institute of Tecnology (MIT), na década de 60, a partir de pesquisas feitas pelos matemáticos Seymour Papert e Wallace Feurzeig, diretor da MIT.

As atividades propostas para o SuperLogo foram desenvolvidas com o objetivo de "promover uma aprendizagem ativa, pela qual o aluno, sujeito do processo, é incitado a pensar sobre o problema e a explicitar a solução escolhida da forma que considera adequada segundo seu próprio estilo de pensamento" (CORREIA, 2001, p. 27).

Num primeiro momento, os acadêmicos não sentiram dificuldades em trabalhar com o SuperLogo, mas, à medida que foram aprofundando os conceitos intrínsecos à geometria particular do software, surgiram dúvidas e questionamentos, que, por meio da prática colaborativa, puderam ser resolvidas.

$\mathrm{Na}$ fase avançada do software, que possibilitava o desenvolvimento das fases adidáticas, foram trabalhados procedimentos avançados. Tivemos de aplicar mais atividades para que os acadêmicos pudessem vislumbrar com mais clareza as possibilidades do SuperLogo no Ensino de Matemática.

Em relação aos aspectos positivos, tivemos várias considerações das quais destacamos: o software é detalhado; possibilita a construção de figuras; desenvolve o raciocínio lógico; permite a avaliação contínua dos alunos; reforça conteúdos; a interface é amigável e útil e é boa ferramenta para o docente. 
Os aspectos negativos destacados foram: necessita de um número significativo de aulas para manuseá-lo; exige bastante explicação para que os alunos entendam a linguagem de programação; é mais trabalhoso do que dar aula; a linguagem de programação é difícil; e falta aplicação prática.

Ao término das atividades os acadêmicos foram instigados a institucionalizar as contribuições do software a sua formação. Para cinco acadêmicos o software contribui para o desenvolvimento do Ensino de Matemática, principalmente no aprimoramento dos conceitos geométricos.

\section{Planilhas eletrônicas}

Finalizando os trabalhos, escolhemos apresentar um software não dedicado para mostrar aos acadêmicos as potencialidades que esses programas possibilitam ao Ensino de Matemática.

As atividades propostas, diferentemente das anteriores, visavam criar nos acadêmicos um processo de reflexão sobre a maneira de empregar uma planilha eletrônica para desenvolver conceitos matemáticos.

Inicialmente, ao explicitarmos as ferramentas de uma planilha eletrônica, percebemos que os participantes não visualizam o emprego da mesma como ferramenta de apoio à matemática. Tal constatação fica evidenciada nas interações ocorrida no grupo de discussão da disciplina. Apresentamos a seguir um trecho dessa interação.

(13/9/2012 16h50min) - Acadêmico D: Nossa! Nunca havia percebido a possibilidade de utilizar o Excel na matemática.

(13/9/2012 16h51min) - Acadêmico B: Eu sempre vi as pessoas usando para criar tabelas, mas não via aplicabilidade na matemática,

(13/9/2012 16h51min) - Acadêmico G: Mas será que os alunos vão entender as ferramentas do Excel? Eu mesmo me sinto confuso às vezes.

(13/9/2012 16h52min) - Acadêmico E: Já estou vendo possibilidades de empregar matrizes com planilhas lá na escola do estágio. 
Verificamos que, à medida que os acadêmicos foram conhecendo as ferramentas e as potencialidades das planilhas no Ensino de Matemática, eles se sentiram motivados a descobrir novas possibilidades de manusear o software.

Assim, ao sentirem-se desafiados a buscar novas propostas e maneiras de uso das planilhas, percebemos um processo de significação da aprendizagem, ocorrendo uma aprendizagem significativa.

Observamos que os participantes conseguiram institucionalizar perfeitamente o conteúdo dentro dos parâmetros matemáticos e fazer a transposição dessa linguagem para o seu uso em uma planilha eletrônica.

A avaliação final do software mostra que seis acadêmicos o utilizariam em sua prática docente, pois consideram que o programa é amplo e possibilita o desenvolvimento de vários conceitos matemáticos. Um aspecto negativo, destacado pelo investigador, foi o fato de os acadêmicos não terem observado as potencialidades do software no Ensino de Estatística.

\section{O que dizem os mapas conceituais finais?}

Ao término de aplicação desta investigação, foi solicitado aos acadêmicos que refizessem o mapa conceitual sobre tecnologias, conforme destacado na Figura 2. Para construir esse mapa eles poderiam mobilizar todos os conhecimentos adquiridos ao longo dos meses do experimento. Analisamos o mapa conceitual desenvolvido por cada acadêmico e realizamos um comparativo com o mapa inicial. 
Figura 2 - Mapas conceituais finais sobre tecnologia
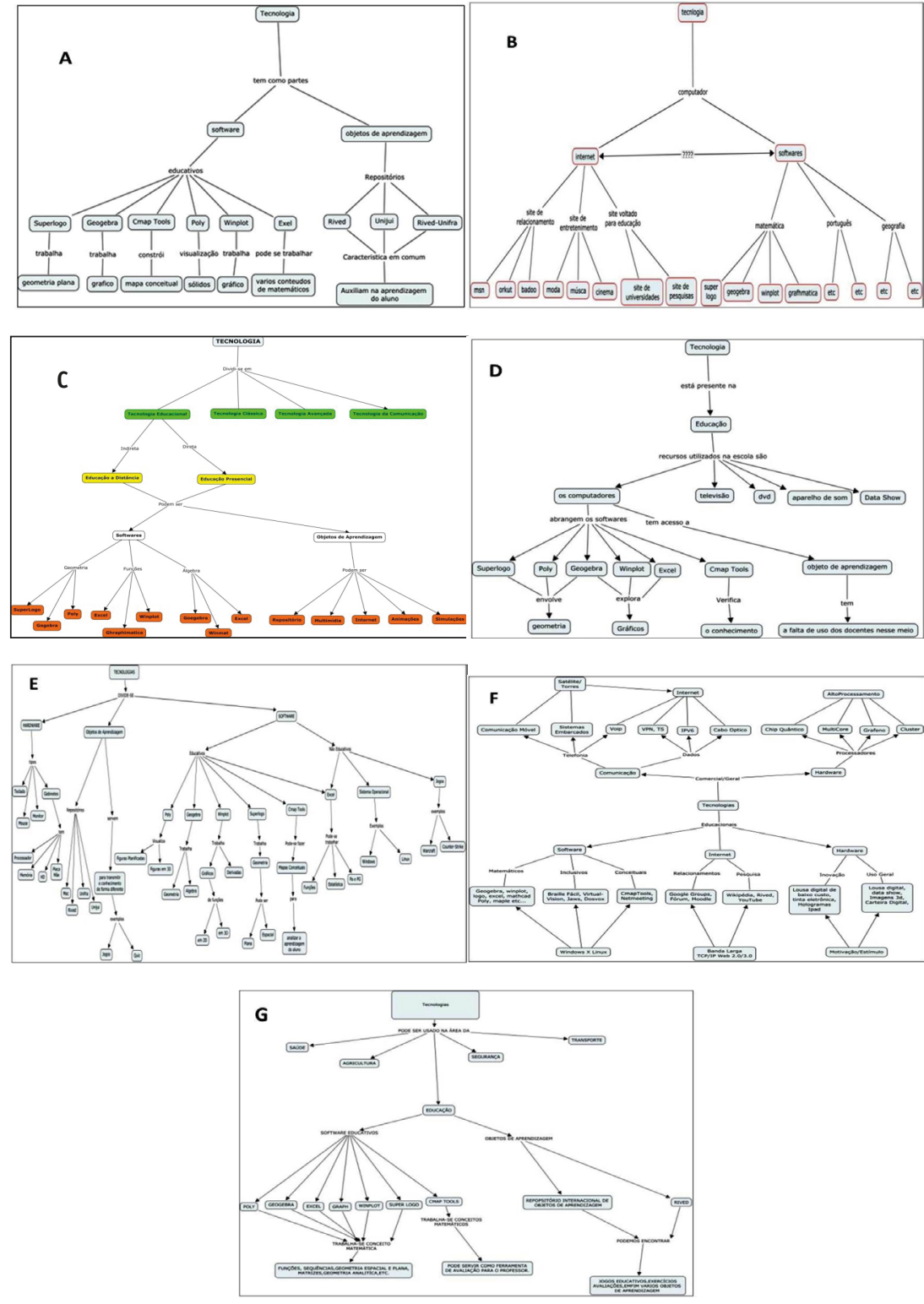
$\mathrm{O}$ acadêmico A, em seu mapa inicial, apresenta uma tentativa de explicitar suas considerações sobre tecnologias, relacionando-as com a escola e a universidade, mas suas inferências ficam inconclusivas (ver Figura 1-A). O mapa final do acadêmico apresenta um aperfeiçoamento da linguagem e do conhecimento sobre a temática explorada, conforme destacado na Figura 2-A.

No mapa, percebemos que o acadêmico tentou descrever tecnologias apenas com suas representações ligadas ao que foi apresentado na disciplina, ou seja, o uso de softwares educacionais e os programas apresentados em sala.

Notamos que houve uma mudança de rumo de um mapa para outro, sendo o segundo mapa muito específico. Ocorreu, todavia, um agregamento de outros elementos que não estavam presentes no mapa inicial. Essa constatação demonstra um amadurecimento de seu processo de aprendizagem, fazendo com que a tecnologia se torne significativa em sua vida. Ao compararmos os mapas, fica evidente que o participante passou por um processo de reavaliação do que já achava que sabia, incluindo em suas estruturas cognitivas novas informações necessárias para modificar a condição inicial, tornando sua Aprendizagem Significativa.

O mapa inicial do acadêmico B (ver Figura 1-B) também apresentou uma concepção tecnológica tentando relacionar Educação ao desenvolvimento social, mas não destacou de forma explícita essa relação, pois possuía uma visão limitada sobre o uso do computador na Educação. No seu mapa conceitual final, conforme a Figura 2-B, verificamos que ele tenta associar os conteúdos desenvolvidos durante a disciplina. Segundo sua avaliação, a disciplina Informática Aplicada ao Ensino de Matemática permitiu uma visão mais abrangente dos conteúdos tecnológicos e sua aplicação na Educação.

Para o discente, o seu primeiro mapa se mostra com conceitos insuficientes e limitados de tecnologias, mas, no segundo mapa, ele passou a perceber que a tecnologia está relacionada a tudo, principalmente na Educação. Observamos uma evolução do mapa inicial para o final, mas ainda fica evidenciada uma concepção reducionista do uso do computador na Educação. 
Analisando o mapa inicial do acadêmico C, percebemos sua preocupação em relacionar tecnologia e Educação, ficando evidenciados seus aspectos cognitivos quando se aplica tecnologias na Educação. O problema identificado nesse mapa é a concepção dissociada das tecnologias as outras situações cotidianas (ver Figura 1-C). Sobre o mapa final, o acadêmico destaca todos os seus conhecimentos adquiridos na disciplina e traz para seu mapa uma visão mais complexa do uso tecnológico, centrando-se, principalmente, nas tecnologias educacionais, conforme destacamos no mapa da Figura 2-C.

Observamos uma visão mais pensada sobre o termo tecnologia e um aprofundamento na informática educacional. O que nos chamou atenção no mapa do acadêmico é a separação em Educação a Distância e Educação Presencial, e a junção de ambas nos conceitos apreendidos. Percebemos que esse participante estabelece relações entre ideias que já fazem parte de sua estrutura cognitiva, e, no decorrer desse processo, novos conceitos são estabelecidos ou reorganizados, proporcionando novos significados.

No acadêmico D percebemos uma preocupação em tentar relacionar tecnologias com outras aplicações cotidianas, como destacado na Figura 1-D. Para o acadêmico, o objetivo de seu mapa era demonstrar a aplicabilidade das tecnologias no cotidiano, porém, para ele, faltou um maior aprofundamento e conhecimento. Em seu mapa final, o acadêmico foca inteiramente na Educação, fugindo da proposta inicial, mas utilizando os conhecimentos desenvolvidos no decorrer da disciplina (ver Figura 2-D).

Percebemos no mapa final do acadêmico uma inquietação em relacionar todos os conteúdos desenvolvidos na fase investigativa e a preocupação em destacar que a escola possui outros recursos tecnológicos, não se limitando apenas ao computador. Notamos em seu mapa uma ressignificação de conceitos e o desenvolvimento de uma Aprendizagem Significativa.

$\mathrm{O}$ acadêmico E tenta, em seu mapa inicial, criar uma relação entre tecnologias e sua presença no cotidiano das pessoas. Dentre os mapas iniciais, este foi o que mais se aproximou do ideal, conforme apresentado na Figura 1-E. Em seu mapa final (ver Figura 2-E), o acadêmico também apresentou suas ideias de forma abrangente. 
Notamos que esse mapa foge de sua proposta inicial, retendo-se ao uso da tecnologia somente para a Educação. Ele tenta apresentar alguns conceitos técnicos relacionados a hardware, mas mostra sua forte argumentação no uso dos softwares, inclusive apresentando uma ligação entre os educacionais e os não dedicados.

Observamos que, com a mobilização de suas estruturas cognitivas, deu-se um novo significado ao termo "tecnologia" a partir das ideias apresentadas durante a fase investigativa. $\mathrm{O}$ acadêmico deixa evidente em seu mapa e em suas colocações que o processo de aprendizagem significativa é desenvolvido por meio da interação entre ideias, que podem ser representadas simbolicamente de modo não arbitrário e substantivo.

O acadêmico F, por se tratar de professor de montagem e manutenção de computadores, elaborou um mapa inicial (Figura 1-F), mais técnico, voltado para uma aplicação educacional profissional. O mapa final do acadêmico apresenta todas as características técnicas presentes no mapa inicial e complementa-o de forma significativa, agregando conceitos educacionais.

O seu mapa final é confuso, pois ele apresenta conceitos técnicos e educacionais na mesma figura. Tem-se a impressão de uma má distribuição de conceitos, pois ele expõe a tecnologia de forma central e cria dois segmentos distintos de sua aplicação (técnica e educacional), mas sempre trazendo para o lado educacional sua visão profissional (ver Figura 2-F). Apesar de uma má distribuição dos conceitos, os objetivos educacionais ficam devidamente explicitados em seu mapa. Outra questão destacada é que o acadêmico traz à tona o uso de softwares educacionais inclusivos e uma concepção do uso de softwares livres.

Para o acadêmico, esse segundo mapa apresenta uma visão mais clara do uso das tecnologias na educação, e ele explica que, em sua prática profissional, não estava preocupado com a forma de apresentação dos conceitos.

Por fim, o acadêmico $G$ era considerado o mais cético quando tratávamos do uso de tecnologias no Ensino de Matemática. Em seu primeiro mapa fica evidenciada uma visão tradicionalista da informática na Educação (ver Figura 1-G). Após a interação com os softwares e as atividades propostas na pesquisa, percebemos uma visão mais educacional do uso das tecnologias, além de uma evidência de sua aplicação em outros campos profissionais (ver Figura 2-G). 
Para esse acadêmico em específico, notamos uma grande mudança no que se refere ao uso das tecnologias. Ele deixou de ter uma visão tradicional da temática e abriu seu leque de conhecimentos para outras áreas, principalmente na Educação, ou seja, ele ressignificou sua aprendizagem, trazendo novos conceitos na interação com os softwares. A partir de ações com o meio, suas estruturas cognitivas evoluíram e se organizaram, trazendo à tona uma Aprendizagem Significativa.

\section{O questionário final de pesquisa}

O questionário final foi composto de três questões com o objetivo de investigar o que os acadêmicos pensaram acerca da disciplina Informática Aplicada ao Ensino de Matemática, bem como a percepção que eles tiveram ao trabalhar com softwares educacionais matemáticos para resolução das atividades investigativas.

A seguir destacamos essas questões, realizando uma análise das respostas apresentadas.

1) A disciplina de Informática Aplicada ao Ensino de Matemática contribuiu para sua formação docente?

( ) Sim ( ) Não ( ) Talvez

Justifique:

As respostas apresentadas por todos os acadêmicos foram de que a disciplina contribuiu para a formação inicial. Como justificativa, tivemos várias opiniões, conforme apresentamos a seguir:

Acadêmico A: Através dessa disciplina pude perceber que a matemática pode ser ensinada com outros recursos tecnológicos;

Acadêmico B: Pude conhecer mais softwares auxiliando a minha prática docente, principalmente no estágio;

Acadêmico $C$ : Teve grande importância para minha formação; deveria ter sido apresentada logo no início do curso;

Acadêmico D: Aprendi muito com a relação dos conteúdos matemáticos e o uso de tecnologias educacionais; 
Acadêmico E: Pude aprender muito na utilização de recursos tecnológicos na aula de Matemática;

Acadêmico F: Foi uma disciplina proveitosa, mas conhecia a maioria dos softwares;

Acadêmico $G$ : Obtive ferramentas para transmitir conteúdos matemáticos em sala de aula.

As respostas trazem elementos essenciais para nossa análise, pois destacam a importância dessa disciplina na formação acadêmica e uma necessidade de que a mesma seja apresentada mais cedo no curso, pois destacam ferramentas que podem contribuir no desenvolvimento da prática pedagógica, principalmente do Estágio Supervisionado. Todos afirmaram a solidificação dos conceitos matemáticos ao longo do experimento. Isso serve como elemento para validar que as atividades desenvolveram as estruturas cognitivas dos participantes promovendo uma Aprendizagem Significativa

2) De qual software trabalhado em aula você mais gostou? Justifique.

Tivemos as seguintes respostas:

- Quatro alunos elegeram o Geogebra como o melhor software, pois é mais interativo, de fácil manipulação e possibilitava trabalhos com diferentes conceitos.

- Um aluno considera o Winplot, pois possibilita a construção de gráficos bidimensionais e tridimensionais;

- Um aluno apontou o SuperLogo, pois desenvolve o raciocino lógico;

- Um aluno destacou o CmapTool, que, apesar de não ser um software de análise nesta pesquisa, possibilita uma verificação de como o aluno está aprendendo o conteúdo;

- Não tivemos avaliação para o software Poly, possivelmente por sua simplicidade de manipulação;

- Também não tivemos avaliação para o software não dedicado de Planilhas Eletrônicas, provavelmente em razão da necessidade de um domínio pleno da linguagem matemática específica do programa. 
3) Destaque os pontos positivos e negativos do uso das tecnologias no ensino de matemática.

Apresentaremos no Quadro 1 uma síntese das respostas dadas e esta questão.

Quadro 1 - Pontos positivos e negativos do uso de tecnologias

\begin{tabular}{|c|c|c|}
\hline \multirow[t]{2}{*}{ Acadêmico } & \multicolumn{2}{|c|}{$\begin{array}{c}\text { Destaque os pontos positivos e negativos do uso de tecnologias } \\
\text { no ensino de matemática }\end{array}$} \\
\hline & Positivo & Negativo \\
\hline A & $\begin{array}{l}\text { As aulas tornam-se mais dinâmi- } \\
\text { cas e interessantes para o aluno. }\end{array}$ & $\begin{array}{l}\text { É necessário um maior planejamento do } \\
\text { professor e ele precisa estar disposto a } \\
\text { trabalhar com tecnologias. }\end{array}$ \\
\hline B & $\begin{array}{l}\text { A tecnologia é ótima como fer- } \\
\text { ramenta para o ensino de mate- } \\
\text { mática. }\end{array}$ & $\begin{array}{l}\text { Faz-se necessário que o professor tenha } \\
\text { uma formação para trabalhar com esta } \\
\text { metodologia. }\end{array}$ \\
\hline $\mathrm{C}$ & $\begin{array}{l}\text { Mais interesse nas aulas por parte } \\
\text { dos alunos. }\end{array}$ & $\begin{array}{l}\text { O laboratório deve ter máquinas sufi- } \\
\text { cientes para atender toda a demanda de } \\
\text { alunos matriculados por sala. }\end{array}$ \\
\hline $\mathrm{D}$ & $\begin{array}{l}\text { Os alunos mostraram-se mais } \\
\text { interesse em trabalhar com a } \\
\text { matemática. }\end{array}$ & Vários computadores com problemas. \\
\hline $\mathrm{E}$ & $\begin{array}{l}\text { Melhora o raciocínio lógico e os } \\
\text { processos matemáticos mentais. }\end{array}$ & $\begin{array}{l}\text { Pode-se perder tempo em ensinar o } \\
\text { aluno com tecnologias. }\end{array}$ \\
\hline$F$ & $\begin{array}{l}\text { Interação dos alunos e a abertura } \\
\text { de novas propostas metodoló- } \\
\text { gicas. }\end{array}$ & $\begin{array}{l}\text { Pode gerar no aluno uma falsa ideia de } \\
\text { que não precisa da aula tradicional, mas } \\
\text { somente da tecnologia. }\end{array}$ \\
\hline G & $\begin{array}{l}\text { Faz os alunos interagirem de } \\
\text { forma mais significativa com a } \\
\text { máquina. }\end{array}$ & $\begin{array}{l}\text { Pude perceber que existem muitos } \\
\text { alunos à margem da tecnologia, não } \\
\text { possuindo conhecimento algum sobre } \\
\text { o uso dos equipamentos. }\end{array}$ \\
\hline
\end{tabular}

Fica evidenciado que os acadêmicos compreenderam a necessidade do uso de tecnologias no Ensino de Matemática, pois, como afirmaram, isso fez com que eles se sentissem mais motivados em aprender o conteúdo, tornando as aulas mais dinâmicas, significativas e proporcionando um repensar nas práticas do Estágio Obrigatório. Outro ponto de destaque é que eles compreenderam claramente que um software é um elemento de apoio e não um substituto da atividade docente. 
Em relação aos aspectos negativos, eles destacaram a necessidade constante de planejamento nas aulas com tecnologias digitais, para que esta não seja uma mera reprodução do que acontece em sala de aula. Os laboratórios de informática devem ter máquinas funcionando e em quantitativo suficiente para atender aos alunos. $\mathrm{O}$ acadêmico $\mathrm{E}$ apresentou uma visão de que trabalhar com tecnologias faz perder tempo. Isso realmente acontecerá se não houver planejamento por parte do docente. Um ponto destacado pelo acadêmico $\mathrm{G}$ sobre a existência de alunos à margem da tecnologia, faz com que realmente concordemos com essa preocupação, pois estão em uma região, em que não existe política pública de informatização das escolas públicas, tampouco a possibilidade de uma inserção da tecnologia na vida da comunidade.

De modo geral, as respostas apresentadas no questionário permitiram que avaliássemos, positivamente, os instrumentos escolhidos na primeira etapa desta pesquisa, ou seja, o trabalho com mapas conceituais, o desenvolvimento de atividades investigativas com o uso da TSD, a dinâmica proporcionada pelos softwares e os questionários preenchidos são relevantes ao estudo de suas interferências no processo educacional.

Dessa forma, conseguimos trazer à tona elementos que pudessem responder parte do objetivo proposto pela pesquisa, isto é, demonstrar que ambientes mediados por computadores contribuem na formação inicial dos alunos do curso de Licenciatura em Matemática.

Assim, alcançamos um ambiente de ensino, aprendizagem, educação e cidadania no qual o próprio acadêmico pode perceber, mesmo que de forma implícita, que o uso de tecnologias digitais deve ser visto em sua dimensão de instrumento facilitador e balizador de mudanças sociais.

\section{Considerações Finais}

Os resultados obtidos com aquela pesquisa trouxeram respostas que permitiram concluir que o objetivo geral deste estudo foi alcançado, pois os acadêmicos conseguiram compreender as necessidades do uso de recursos tecnológicos como ferramentas para o desenvolvimento de Aprendizagens Significativas. 
Os mapas conceituais iniciais sobre tecnologias mostraram um grupo que nunca teve contato com tecnologias durante sua formação inicial. Cabe destacar que esse foi o último semestre desses acadêmicos e as disciplinas tecnológicas que tiveram durante o curso somente apontavam para uma visão técnica.

As aulas foram divididas em dois ambientes bem-definidos: interação na atividade investigativa e execução das tarefas nos softwares educacionais. Esse intercâmbio mostrou aos acadêmicos quais os conceitos que poderiam ser desenvolvidos com o uso dos programas em destaque. Durante essa interação, ficaram evidentes as fases adidáticas propostas por Brousseuau (1996), pois os acadêmicos deveriam realizar as tarefas nos softwares na fase de ação, formular e estabelecer conjecturas e validar suas respostas com o auxílio do software. Em alguns momentos foi exigida, no decorrer dessa etapa, a institucionalização dos conceitos mediante preenchimento de relatórios.

Nos softwares aplicados o tema mais recorrente foi o de funções, mas outras temáticas também foram abordadas, como geometria (plana, espacial e analítica), derivadas, integrais, sólidos geométricos, matrizes, entre outras. Processos mentais também foram privilegiados, tais como generalização, abstração, dedução, indução, raciocínio lógico e visualização.

Os mapas conceituais finais demonstraram que foi dado um novo significado ao termo tecnologia, pois apresentaram características ausentes nos mapas iniciais. O aparecimento de novos conceitos e a reorganização de outros, evidenciam uma nova reestruturação da cognição num processo de Aprendizagem Significativa.

Os instrumentos de coleta de dados da primeira etapa da pesquisa, articulados com o referencial teórico, possibilitaram que entendêssemos o contexto e o cenário que os acadêmicos vivenciaram. A partir das análises das interações com os softwares, identificamos uma ressignificação dos processos mentais.

Acreditamos que as potencialidades dos softwares contribuíram para uma ação investigativa intensa, demonstrando que, durante a utilização dos programas, os acadêmicos construíram novos conhecimentos. Os dados coletados mostram que a vontade de utilizar novos recursos metodológicos em suas práticas educativas se aprofunda com o apoio das tecnologias. 
O questionário final possibilitou o nosso entendimento do que os acadêmicos pensavam sobre o uso de tecnologias digitais no Ensino de Matemática. Todos destacaram que o emprego do computador e a Matemática possuem uma estreita ligação. A interação entre esses elementos possibilitou ao acadêmico obter um ambiente no qual se sinta desafiado e instigado a desenvolver sua própria aprendizagem em um processo ativo.

Particularmente, percebemos que a inserção das tecnologias na Educação demonstra a necessidade de prepararmos nossos professores, na formação inicial e continuada, para lidarem com situações em que as tecnologias digitais sirvam de ferramentas para tornar a aprendizagem dos alunos significativa.

Sabemos que muitos cursos de formação não apresentam um intercâmbio das disciplinas tecnológicas com as disciplinas práticas. É possível mudar essa realidade. Para que isso ocorra, todavia, as instituições de ensino devem investir no desenvolvimento dos saberes docentes para o uso das tecnologias digitais na formação inicial, por meio de um saber curricular que conecte tecnologia com a prática educativa.

\section{Referências}

AUSUBEL, D. P. Education psychology: A cognitive view. Nova York: Rinehart and Winston Inc., 1968.

AUSUBEL, D. P.; NOVAK, J. D.; HANECIAN, H. Psicologia educativa: um ponto de vista cognoscitivo. México: Ed. Trilhas, 1978.

ALMOULOUD, S. A. Fundamentos da didática da matemática. Curitiba: Editora UFPR, 2007.

BORBA, M. C.; PENTEADO, M. G. Informática e educação matemática. 5. ed. Belo Horizonte: Ed. Autêntica, 2015. (Coleção tendências em educação matemática).

BOGDAN, R.; BIKLEN, S. Investigação qualitativa em educação: uma introdução à teoria e aos métodos. Portugal: Porto Editora, 1994.

BELINE, W.; COSTA, N. M. L. (Org.). Educação matemática, tecnologia e formação de professores: algumas reflexões. Campo Mourão: Editora da Fecilcam, 2010. 
BRASIL. Resolução CNE/CP n $n^{o}$ 03/2003. Institui Diretrizes Curriculares Nacionais dos Cursos de Graduação em Matemática. Brasília: Conselho Nacional de Educação, 2003.

. Parecer $C N E / C P n^{\circ} 2 / 2015$. Institui Diretrizes Curriculares Nacionais para a Formação Inicial e Continuada dos Profissionais do Magistério da Educação Básica. Brasília: Conselho Nacional de Educação, 2015.

BROUSSEAU, G. Fundamentos e métodos da didáctica da matemática. In: BRUN, J. Didática das matemáticas. Tradução Maria José Figueiredo. Lisboa: Instituto Piaget, 1996.

CORREIA, L. H. A. Computador Tutelado. Lavras: UFLA/FAEPE, 2001.

LÜDKE, M.; ANDRÉ, M. E. D. A. Pesquisa em educação: abordagens qualitativas. São Paulo: EPU, 2013.

MARCELO GARCÍA, C. Formação de professores para uma mudança educativa. Portugal, Porto: Porto Editora, 1999.

MOREIRA, M. A.; MASINI, E. F. S. A aprendizagem significativa: a teoria de David Ausubel. São Paulo: Moraes, 1982.

MOREIRA, M. A. Ensino e aprendizagem: enfoques teóricos. São Paulo: Editora Moraes, 1985.

Aprendizagem significativa em mapas conceituais. Porto Alegre: UFRGS; Instituto de Física, 2013.

MOTTA, M. S. O estágio supervisionado na formação do professor de matemática no contexto das tecnologias educacionais. 2012. 354 f. Tese (Doutorado em Ensino de Ciências e Matemática) - Universidade Cruzeiro do Sul, São Paulo, 2012.

MOTTA, M. S.; SILVEIRA, I. F. Estágio supervisionado e tecnologias educacionais: estudo de caso de um curso de Licenciatura em Matemática. Educação Matemática Pesquisa, São Paulo, v. 14, n. 1, 2012.

SHULMAN, L. S. et al. 150 ways of knowing: Representations of knowledge in teaching. In: CALDERHEAD, J. (Org.). Exploring teachers thinking. Grã-Bretanha: Cassel Educational Limited, 1987. p. 104-124.

TAJRA, S. F. Informática na educação: o professor na atualidade. São Paulo: Érica, 2012. TUCKMAN, B. W. Manual de investigação em educação. Lisboa: Fundação Calouste Gulbenkian, 1994.

Recebido em: 5/5/2017

Aceito em: 12/7/2017 